\title{
(Des)naturalizando Sujeitos e Práticas na Escola: Foucault para além de vigiar e punir
}

\author{
Gabriel Nascimento da Silva Santos' \\ Ederson Luis Silveira" \\ João Paulo de Lorena Silva'
}

'Universidade Federal de Minas Gerais (UFMG), Belo Horizonte/MG - Brasil

"Universidade Federal de Santa Catarina (UFSC), Florianópolis/SC - Brasil

RESUMO - (Des)naturalizando Sujeitos e Práticas na Escola: Foucault para além de vigiar e punir. O presente trabalho, qualitativo de cunho descritivo, parte de reflexões acerca das contribuições de Michel Foucault no campo educacional. Considerando a temática do cuidado de si, tem-se por objetivo apresentar de que modo a desnaturalização de saberes emerge como tema para além das discussões acerca da normalização e disciplinamento dos sujeitos. Por meio da articulação entre processos de subjetivação e práticas do cuidado de si, novas questões e novas categorias são mobilizadas para (re)pensar a pauta das discussões em torno da educação na atualidade.

Palavras-chave: Cuidado de Si. Educação. Atualidade.

ABSTRACT - (De)naturalised Subjects and Practices in School: Foucault as well as discipline and punish. The present work, of qualitative descriptive, part of reflections about the contributions of Michel Foucault in the educational field. Considering the theme care of yourself, has as objective to present how the denaturalization of knowledge emerges as theme beyond discussions about standardization and discipline of the subject. Through the joint between processes of subjectivation and si care practices, new issues and new categories are mobilized to (re) thinking about the agenda of discussions around education today.

Keywords: Care of Yourself. Education. Actuality.

Educação \& Realidade, Porto Alegre, v. 41, n. 4, p. 1275-1287, out./dez. 2016.1275 http://dx.doi.org/10.1590/2175-623653313 
(Des)naturalizando Sujeitos e Práticas na Escola

\section{Situando o Percurso}

"Quem é capaz de ter a coragem da verdade? E qual é a educação necessária? Problema técnico: qual vai ser, por conseguinte, na educação, o ponto no qual deve se pôr ênfase?" (Foucault, 2004, p. 277). A questão proposta por Foucault se faz cada vez mais atual, e o presente trabalho, propõe explorar algumas dimensões dos usos recentes do pensamento foucaultiano pelo campo educacional brasileiro a partir do pressuposto de uma nova recepção de suas ideias, impulsionada pela edição dos cursos inéditos proferidos no Collège de France entre 1982 e 1984, focando, sobretudo a temática do governo de si e dos outros.

Nesse sentido, a reflexão sobre o si mesmo, subjacente à ética do cuidado, permite vislumbrar duas pedagogias: uma que se volta para a produção do sujeito e outra que visa transformá-lo. Para Castrillón (2003), essa dimensão dualista da educação está presente em quase todas as sociedades e foi localizada com uma precisão analítica surpreendente por Michel Foucault a partir de sua retomada da Antiguidade greco-romana efetuada em seus últimos cursos.

Dessa forma, o objetivo específico deste texto consiste em evidenciar como a tematização em torno do cuidado de si-presente no curso de 1983 - emerge como um possivel caminho de reflexão crítica frente aos desafios da educação na atualidade, especialmente no que tange à relação entre as instituições educativas e os sujeitos jovens, isto é, à educação da juventude e sua relação com a escola - contexto em que os educadores são desafiados a questionarem sua forma de relacionar-se com a condição de ser jovem que se apresenta a eles atualmente. Isso porque, para Juarez Dayrell (2007) - a partir de seu amplo estudo sobre a problematização da condição juvenil atual - a comunidade educacional enfrenta a necessidade de repensar o espaço escolar para poder responder aos desafios que a "juventude" (em seus diversos elementos de constituição social, política e cultural) nos apresenta, em especial sobre o seu processo de engajamento social.

Assim sendo, segundo Humberto Castrillón (2003), ao abordar a noção de cuidado de si Foucault acabou produzindo insights inovadores sobre os processos de subjetivação na educação que, por sua vez, guardam estreitas relações com questões éticas, políticas e pedagógicas. Nesse sentido, tem-se o fio hermenêutico dessa reflexão a partir de duas abordagens. Inicialmente, será apresentada uma breve contextualização do pensamento de Foucault bem como de uma visão geral sobre sua trajetória de pensamento. Em seguida, analisaremos como o seu dizer parresiástico em torno do cuidado de si, balizado no diálogo do Alcibíades, de Platão, pode indicar novos elementos para a problematização da educação brasileira e, consequentemente, as implicações dessa reflexão para o debate em torno da formação humana na contemporaneidade. Será utilizada como obra-chave A Hermenêutica do Sujeito que reúne as últimas aulas acerca da retomada da moral greco-romana por Foucault (2004).

1276 Educação \& Realidade, Porto Alegre, v. 41, n. 4, p. 1275-1287, out./dez. 2016. 


\section{Nos Passos de Foucault}

De acordo com Alfredo Veiga-Neto (2005) a influência do pensamento foucaultiano na educação pode ser compreendida a partir dos impactos da publicação da edição brasileira de Vigiar e punir em 1977. Nesse momento, produziram-se inúmeros trabalhos que estiveram pautados a partir da questão do disciplinamento e da normalização. Uma ênfase que permanece "[...] como referência para muitos estudos históricos, sociológicos e pedagógicos sobre a Educação” (Veiga-Neto, 2009, p. 13).

A partir das propostas de Carvalho (2010) e de Veiga-Neto (2009), podemos dividir o trabalho filosófico de Foucault em três eixos hermenêuticos principais que perpassam fundamentalmente o grande intuito foucaultiano de construir a ontologia histórica de nós mesmos, ou ainda, uma ontologia do presente. Nesse sentido, o interesse de Foucault era o de construir um diagnóstico do presente, isto é, analisar o modo ou o processo pelo qual o sujeito torna-se sujeito, através do qual são construídos diversos tipos de instituições e de culturas. Para isso, tais eixos são assim compreendidos: o saber (ser-saber), a análise do conhecimento; o poder, entendido por Foucault como a ação de uns sobre os outros (ser-poder) e a ação do indivíduo consigo próprio (ser-consigo).

A fim de que tenhamos uma compreensão mais profunda a respeito de cada um dos níveis se faz necessário retomarmos a inquietação maior de Foucault, a saber, sobre a ontologia/diagnóstico do presente. Esta consiste então numa análise crítica em relação a nós mesmos. Podemos perceber um deslocamento daquela questão kantiana de quem somos nós? para uma outra e mais ampla indagação - já proferida por Nietzsche (2009) - “[...] que se passa conosco mesmo?". De fato, esse novo posicionamento do pensar coloca em aberto o sentido e o valor das coisas que acontecem conosco no presente. Ora, o que importa então para Foucault não é descobrir o que somos nós, sujeitos modernos, mas sim a grande e instigante pergunta: como chegamos a isso que somos? ou ainda o que fizeram de nós?

A direção argumentativa, nesta parte inicial da reflexão, é a de ressaltar - segundo o projeto filosófico de Foucault - que as sociedades ocidentais tal como foram organizadas a partir dos séculos XVIII e XIX são, estruturalmente, disciplinares. Tal caráter disciplinar é exercido no seio dessas sociedades na medida em que há uma íntima articulação entre aquelas três esferas (o Estado liberal, as relações de produção capitalistas e a moralidade da Igreja católica) no que se refere à construção da cultura e do homem modernos. É interessante notar que essa construção do homem e da cultura modernos é levada à prática justamente no seio destas instituições e contam ainda - e especialmente nesse estudo - com o auxílio da escola e da repressão de forças organizadas que juntas reclamam e reforçam um estilo de vida considerado correto, e em função disto, constroem um aparato capaz de enquadrar,

Educação \& Realidade, Porto Alegre, v. 41, n. 4, p. 1275-1287, out./dez. 2016.1277 
disciplinar, formatar ou, nos termos de Foucault, normatizar as pessoas em um formato ideal.

Neste contexto, para Silveira (2014b), a disciplinarização dos sujeitos não parte somente do exterior (como efeito de uma contingência histórico-social sobre o sujeito), mas também das relações do sujeito em relação a si mesmo. Desse modo, vale reiterar que "[...] algumas vezes, o poder disciplinar está tão atrelado à vida social que se torna difícil conhecer sua ordem de aparecimento, porém, ele passa a ser percebido a partir de seus efeitos nos corpos disciplinados" (Silveira, 2014a, p. 5). Podemos encontrar tal constatação feita por Foucault a partir das suas análises em torno das relações entre poder e saber, explicitadas, especialmente, em obras como Vigiar e Punir (2009a), e História da Sexualidade I: a vontade de saber (2009b).

Em seus últimos trabalhos - isto é, em sua terceira fase metodológica - Foucault se propõe o desafio de propiciar um tipo de relação do indivíduo consigo próprio (ser-consigo) que se estabeleça contrariamente e denuncie a suposta universalidade de todo fundamento de um sujeito apriorístico, que evite que as relações de poder se configurem a partir de códigos homogeneizadores em estados de dominação e que se constitua sem recorrer a uma verdade anterior. Segundo Foucault (1994, p. 732), a necessidade se torna colocar o sujeito no centro da reflexão, porém, "[...] um sujeito que deve estar livre de toda moral orientada por um código, livre de todos os atributos que lhe foram impostos pelo saber moderno e pelo poder disciplinar e normalizador". Isso se dá, sobretudo, na instituição social escola que, nesse caso, visa à uniformização de um determinado tipo de indivíduo e de sociabilidade.

De fato, o retorno à moral grega, inclusive com reativação de conceitos fundamentais da filosofia socrático-platônica, balizará também o momento final da trajetória de Foucault no College de France. É justamente no âmbito da problemática histórica do preceito filosófico-moral do cuidado de si nas culturas clássica e helenística que terá lugar, nos dois cursos finais, o estudo da parresia antiga. Nesse sentido, em $O$ governo de si e dos outros (2011), o foco maior está sobre a parresia política. Em nossas reflexões adotamos como caracterização de (re) leitura foucaultiana da educação o sentido da parresia política em seus dois significados, tanto como palavra verdadeira proferida pelo cidadão perante a assembleia (democrática) - que seria para nós hoje, a palavra de Foucault - e como a palavra verdadeira proferida pelo filósofo perante o governante a fim de conduzi-lo a bem governar a si mesmo e à cidade (autocrática) - como veremos a orientação de Sócrates ao jovem Alcibíades.

Como indica o trabalho de Andrés Peña (2003), a tematização do cuidado de si no pensamento tardio de Foucault põe em cena um gesto pedagógico radical. Para esse autor, Foucault apresenta uma análise inovadora das possibilidades de constituição do sujeito tomando como ponto de partida a noção de si mesmo para diferenciar o sujeito das prá- 
ticas de subjetivação ética e do sujeito epistêmico. Com isso, diferentemente do que se observa nas obras publicadas do autor nos cursos do Collège de France, podemos identificar o acesso a outras formas de educar o sujeito através do preceito do cuidado de si. Desse modo, por meio de articulações entre processos de subjetivação e de práticas do cuidado de si novas questões e novas categorias são mobilizadas para repensar a pauta dos estudos educacionais na atualidade.

\section{(Re)leituras do Conceito Socrático-Platônica acerca do Cuidado de Si}

No diálogo Alcibíades, de Platão (2007), as interrogações feitas por Sócrates sobre em que consiste o bom governo levam o jovem ateniense a perceber seu total estado de ignorância no que diz respeito ao significado de bem governar. Dessa forma, percebe-se claramente que se Alcibíades quisesse governar os demais (e governar com qualidade) seria preciso governar a si mesmo cuja condição fundamental seria, então, uma crítica a si mesmo, uma crítica que se dirija à própria sociedade, à cultura instituída e à própria formação recebida.

Assim, uma prática refletida da liberdade, para acentuar outro argumento de Foucault (2004), não é possível sem uma perspectiva crítica. Temos nisso um dos primeiros pressupostos da questão do "cuidado de si” (Platão, 2007). Nesse sentido, Foucault (2004) menciona que é preciso "[...] ocupar-se consigo mesmo para poder governar; ocupar-se consigo, na medida em que não se foi suficiente e convenientemente, governado". Um pouco mais adiante, firma ainda que: "É a primeira teoria e, pode-se mesmo dizer, (entre) todos os textos de Platão, a única teoria global do cuidado de si" (Foucault, 2004, p. 57-58).

A partir disso, para uma melhor compreensão acerca da noção de cuidado de si, algumas questões devem ser colocadas, a saber: qual é a significação atribuída à noção do cuidado de si? O que significaria cuidar? O que é então, o si mesmo? Para Foucault, em sua coletânea de cursos reunidos no livro Hermenêutica do Sujeito, a noção do cuidado de si que aqui se aborda está sinalizada em quatro formas de comportamento do jovem Alcibíades:

1. Está relacionada ao desejo do jovem de exercer o poder político e governar os demais. Tem-se aqui então a necessidade do cuidado de si que se expressa como condição de possibilidade para sua condição social se converter em ação política sobre os demais.

2. A noção de cuidado de si está inteira e profundamente ligada à deficiência da educação recebida por Alcibíades. Aqui - junto à Foucault - encontramos o problema da insuficiência da educação ateniense: uma dupla falha pedagógica (escolar e amorosa) do que decorre a necessidade do "ocupar-se consigo".

3. Em terceiro e, especialmente em nossa temática de reflexão contextualizada no cenário educacional brasileiro, temos a questão do

Educação \& Realidade, Porto Alegre, v. 41, n. 4, p. 1275-1287, out./dez. 2016. 1279 
"cuidado de si" ligada à relação do jovem com seu mestre. Isso nos remete à compreensão-chave de que é preciso ocupar-se consigo especialmente quando se está naquela idade crítica, isto é, quando se sai da esfera de passividade em relação aos pedagogos (e, portanto, à escola) para perpassar o período da atividade política, da vida pública civil.

Aprofundamos aqui tal questão, enfatizando a visão foucaultiana de que não há outra via para o desenvolvimento ético do cuidado de si mesmo senão a relação amorosa com o mestre. Mesmo admitindo a "mediação da cidade", o cuidado de si diz sempre respeito a uma pedagogia incapaz de dar conta das suas metas formativas, sobretudo em relação aos jovens. Daí porque, nos termos de Foucault (2004, p. 107), é

$$
\begin{aligned}
& \text { [...] a propósito deste problema, neste vazio institucional, } \\
& \text { neste déficit da pedagogia, neste momento política e ero- } \\
& \text { ticamente conturbado do fim da adolescência e de ingres- } \\
& \text { so na vida adulta - que se formou o discurso filosófico, ou } \\
& \text { pelo menos a forma socrático-platônica do discurso filo- } \\
& \text { sófico. }
\end{aligned}
$$

4. E, por fim, para Foucault, a noção de cuidado de si está relacionada a um movimento de tomada de consciência da própria ignorância. Neste contexto, vale destacar que Alcibíades acreditava que lhe seria bem fácil responder à questão de Sócrates e definir o que é o bom governo da cidade. Assim sendo, ele acreditava poder definir este bom governo "[...] designando-o como aquele que assegura a concórdia entre os cidadãos. E eis que ele sequer sabia o que é a concórdia, mostrando que, ao mesmo tempo, não sabe e ignora que não sabe" (Foucault, 2004, p. 57).

Em síntese, a abordagem foucaultiana da obra Alcibíades permite vislumbrar três questões fundamentais: o exercício do poder político, a pedagogia (prática educacional apoiada na relação) e a ignorância que se ignora.

De fato, para Sócrates o cuidado de si está fundado no conhecimento de si. Podemos afirmar ainda que todo pensamento socrático-platônico em torno do cuidado de si estará em entendê-lo a partir do princípio conhece-te a ti mesmo que consiste, assim, em conhecer a própria alma. Encontra-se, então, o eixo fundamental para a contextualização educacional dessa noção na perspectiva foucaultiana. Ora, com referência a Dal Bosco (2010), pode-se inferir que a alma não possui, para Foucault, o mesmo significado que Platão lhe atribui, ou seja, como alma-substância. Ao contrário, Foucault entende-a como alma enquanto sujeito da ação, isto é, no sentido de uma ação assumida pelo agente em reação às coisas e aos demais. Há, portanto, uma dessubstancialização ou ainda uma historicização do conceito de alma, passando a referir-se ao sujeito finito.

1280 Educação \& Realidade, Porto Alegre, v. 41, n. 4, p. 1275-1287, out./dez. 2016. 
Nesse sentido, a compreensão acerca do cuidado de si alcança aqui sua abordagem maior, de respeito à dignidade humana. Isso significa que não é permitido tomar as pessoas como se elas fossem objetos particulares, que podem ser manipulados ou submetidos às nossas próprias satisfações. O ocupar-se consigo assume dimensão mais ampla que significará ocupar-se consigo enquanto sujeito de, que exerce suas características próprias de sujeito, mas que, acima de tudo, respeita as características do outro. Dessa forma, ocupar-se consigo mesmo assume uma postura de reconhecimento e respeito às características de cada ser humano, pois "[...] querer transformar integralmente uma pessoa significaria descaracterizá-la” (Dal Bosco, 2010 p. 76) A partir da descaracterização é que se torna possível a produção de subjetividades outras pela transformação que parte do enfrentamento para absorver a singularidade enquanto resistência. Para Carvalho (2014), toda transformação na produção de subjetividade parte de um enfrentamento estabelecido diante de pontos de forças em que se torna possível perceber a singularidade como ponto de resistência. Sendo assim, a função-educador se insere (ou deveria se inserir) em contextos de resistência ao uso e à aplicação de formas consolidadas nas experiências de formação tradicionais.

Nesse aspecto, segundo Foucault, o cuidado de si é, com efeito, algo que tem sempre a necessidade de passar pela relação com o outro que é o mestre. Não se pode cuidar de si sem, antes, passar pelo mestre, não há cuidado de si, "[...] não há travessia para a vida público-social, sem a presença do mestre” (Dal Bosco, 2010, p. 73). Tal direcionamento nos incita a observar e a promover, enquanto educadores a desconfiança e a curiosidade em relação ao modo como os saberes foram sendo inseridos no interior de jogos de verdade. Dessa forma, não se trata de desvendar algo que estava oculto. Trata-se, em Foucault, de observar o que é dito. Para Veyne (1982), essa perspectiva torna possível apreender que todo dito engloba preconceitos, reticências, descontinuidades inesperadas que não são conscientes aos enunciadores.

Cabe acentuar que os estudos de cunho genealógico foucaultianos podem contribuir para pensar na possibilidade de promover, nos contextos educacionais, mudanças de subjetividades a partir do desmanche de objetos naturalizados. Isso implica em redirecionamentos e deslocamentos que partem do desconforto com saberes impostos e disciplinarizações estanques e se desdobra em atitudes que vão para além da finitude da (re)produção de práticas naturalizad(or)as. A escola como ambiente disciplina(do)r faz pensar sobre as subjetivações impostas, já que "[...] somos prisioneiros de certas concepções de nós mesmos e de nossa conduta" (Foucault, 1994a, p. 37-38). Por isso, tomando os conceitos de Foucault como ferramentas, poderemos então rumar na direção de estudos "[...] que privilegiem o estudo cada vez mais cuidadoso de práticas educacionais, de práticas didático-pedagógicas, de políticas públicas, de propostas curriculares" (Fischer, 2012, p. 111).

Educação \& Realidade, Porto Alegre, v. 41, n. 4, p. 1275-1287, out./dez. 2016. 
(Des)naturalizando Sujeitos e Práticas na Escola

Portanto, para Foucault, mais do que descobrir quem somos, devemos "[...] recusar o que somos. Devemos promover novas formas de subjetividades refutando o tipo de individualidade que nos foi imposta" (Foucault, 1994b, p. 232), indo em busca da desnaturalização de objetos e saberes para problematizar na escola (e, consequentemente, possibilitar que fora dela, sejam instauradas práticas de reflexões desnaturalizadoras) "[...] os caminhos pelos quais determinados temas, sujeitos, situações, no campo educacional foram historicamente objetivados" (Fischer, 2012, p. 111).

Em relação ao movimento destacado anteriormente podemos afirmar que se trata, para Carvalho (2014), de pensar experiências dessujeitantes na educação. Para isso, segundo o autor mencionado, cabe a nós enquanto educadores problematizar na escola através de ações as formas como os sujeitos foram historicamente constituídos dando lugar então à experimentação “[...] como marca maior do exercício modificador das repetições sujeitantes presentes na atualidade educacional" (Carvalho, 2014, p. 110). Por isso, a importância de pensar o cuidado a partir de um redirecionamento de valores na escola. Dessa forma, para Eizirik (2005), a partir de Sócrates o cuidado de si não está associado a um ato egoísta de cuidar do que se tem, mas cuidar do que se é, ato efetuado a partir da interrogação, tomando consciência, portanto, dos valores que regem a vida das pessoas e também acerca da ignorância que se tem em relação a esse fato.

Neste contexto, cabe destacar a relação dos sujeitos com a verdade. Segundo Foucault (2008), as verdades precisam ser problematizadas, já que foram produzidas, com o passar do tempo, assentando-se sob o solo das certezas e do verdadeiro. Deve-se, portanto, desconfiar das evidências e de tudo o que é colocado como verdadeiro. Para a filósofa Márcia Tiburi (2008), a experiência do pensamento é importante porque a cada vez que é escrita, falada, experienciada é recriada por aquele que enuncia ou escreve tanto quanto pelo interlocutor ou leitor. Isso faz com que sejam levantadas reflexões acerca do papel do intelectual, que não é dizer aos outros o que eles têm que fazer, mas reinterrogar as evidências e naturalizações diversas propondo modos de repensar a produção de sujeitos no tempo em que as discussões estão sendo experienciadas.

Ao assinalar a importância de re-interrogar as evidências, os postulados, o que é dito como pronto e acabado, está-se atacando a inércia do pensamento. Cabe destacar que o intelectual está dentro do espírito de curiosidade que vive em cada um. O exercício de pensar não pode ser engolido por evidências que não passaram por (re)problematizações. Sobre este pano de fundo, trata-se de pensar a ciência (e o modo como os saberes autorizados pelo científico que se assenta sobre o lugar do verdadeiro passível de ser reproduzido) como uma espécie de jogo de verdade que está ligado a “[...] técnicas específicas que os homens utilizam a fim de compreender quem eles são” (Foucault, 2014, p. 266) Des-

1282 Educação \& Realidade, Porto Alegre, v. 41, n. 4, p. 1275-1287, out./dez. 2016. 
sa forma, como a ciência passa a ser percebida como jogo de verdade a partir dos estudos foucaultianos, no contexto teórico em que uma de suas contribuições reside em assinalar que a relação com a verdade é construída historicamente, já que só pode haver “[...] certos tipos de sujeitos do conhecimento, ordens de verdade, domínios de saber, a partir de condições políticas que são como o solo em que se forma o sujeito, os domínios do saber e as relações com a verdade" (Foucault, 1995, p. 32).

Sendo assim, não se trata apenas de pensar sobre o que é possível pensar, mas também de pensar o impensado, o próprio deslocamento que o redirecionamento produz. Se com Foucault (1996) o novo não está no que é dito, mas no retorno de sua volta, é com o retorno das coisas já ditas através olhares reflexivos que extrapolaremos a continuidade de preconceitos e verdades que vão sendo reproduzidas anulando sujeitos e saberes e oprimindo possibilidades de encontro com outros saberes.

Se há os que são autorizados a dizer, também se torna relevante assinalar o direito de voz a todo aquele que estiver disposto a experienciar o pensamento. No contexto educacional, isso se torna imprescindível, já que é necessário possibilitar na escola o surgimento de experiências-limite que possibilitem a liberação de verdades que foram se constituindo como tais com o passar do tempo a partir de repetições e reproduções ad infinitum, pois:

\begin{abstract}
[...] a experiência, e não a verdade, é o que dá sentido à escritura. Digamos, com Foucault, que escrevemos para transformar o que sabemos e não para transmitir o já sabido. Se alguma coisa nos anima a escrever é a possibilidade de que esse ato de escritura, essa experiência em palavras, nos permita liberar-nos de certas verdades, de modo a deixarmos de ser o que somos para ser outra coisa, diferentes do que vimos sendo (Larrosa; Kohan, 2002, p. 5).
\end{abstract}

A esta altura, a escritura pode ser tomada para além do ato de escrever e desdobrar-se no terreno das ações dos sujeitos em relação ao cuidado de si. Vale ressaltar que o tema do cuidado de si em Foucault não se baseia apenas na reprodução da ética antiga na atualidade, pois é preciso assinalar as descontinuidades inerentes a períodos históricos distintos. Sendo assim, é preciso experimentar na escola e fora dela, promover o encontro com a criatividade dos sujeitos e a desconfiança de toda normatização de saberes. Desse modo pode haver a produção de outras subjetividades para além das individuações homogeneizadas historicamente.

Dessa forma, o governo de si tomado tarefa a ser realizada, percebido enquanto um campo organizador e operacional causa um impacto essencial na produção de subjetividades. Sobre as subjetividades, cabe acentuar que essa atitude de abertura para a alteridade de novas experimentações pode possibilitar que haja o deslocamento de subjetividades, o que faz com que o professor possa "[...] tentar modificar o seu posicionamento e tratamento num jogo de forças que não fecha as

Educação \& Realidade, Porto Alegre, v. 41, n. 4, p. 1275-1287, out./dez. 2016.1283 
(Des)naturalizando Sujeitos e Práticas na Escola

possibilidades de formas de subjetividades, pois estas são inesgotáveis" (Carvalho, 2014, p. 111). Ao educador cabe então promover a construção de experiências-limite que emergem como tarefas de subjetivação, visando o sair de si mesmo, promovendo deslocamentos e descaminhos daquele que conhece, no intuito de não ser mais o mesmo. Sendo assim, para Eizirik (2005) os deslocamentos da subjetividade são da ordem do impossível porque se inserem em terrenos de luta, de tensionamentos, de combate, como um processo de dar existência.

Neste contexto de reflexões, caberia então levantar algumas indagações de acordo com a problematização feita por Dayrell (2007) a respeito do lugar da instituição escola no processo de socialização das juventudes: Quem são esses jovens que necessitam urgentemente travar novas relações com seus mestres? De que forma os sujeitos-educadores estão auxiliando nossos jovens na travessia para o laço social, para a vida pública? Estão, de fato, promovendo um espaço de aprendizagem em que o jovem possa elaborar seu próprio projeto de futuro?

Desse modo, ao construir uma problematização da condição juvenil atual, sua cultura, suas demandas e necessidades próprias, Dayrell (2007) procura ressaltar e apontar outros significados sobre o papel que a escola exerce atualmente na vida estudantil dos jovens. Para isso, propõe outra forma de relação entre a juventude e o os educadores na qual a juventude é compreendida como a produção de um novo modo de ser, resultado dos processos de socialização que problematiza posturas pedagógicas naturalizadoras. Cabe, então, para o autor, questionar como se dá a produção do sujeito-jovem nas instituições de ensino, visto que ainda existem lugares em que a condição juvenil não é levada em consideração sob o viés que mencionamos anteriormente.

Para Foucault (1994), o trabalho sobre nossos limites é fundamental e, portanto, entende-se que o cuidado de si está relacionado a uma nova atitude de responsabilidade e abertura, do corpo educador em relação ao processo de formação pedagógico-político e social das juventudes em seu caminho de subjetivação e vínculo com o espaço público. Dessa forma, para pensar experiências dessujeitantes na educação é preciso percebê-las como "[...] ativação de processos educacionais emancipadores que se trata nos domínios do governo de si" (Carvalho, 2014, p. 117), em que se torna necessário "[...] pressentir o perigo que ameaça em tudo que é habitual, e de tornar problemático tudo o que é sólido" (Foucault, 1994, p. 612). É preciso interrogar o conformismo e desconfiar das acomodações, pois o comodismo e o conformismo presentes em nossa cultura refletem o impacto das condições de formação a partir de representações dominantes. É um problema reincidente e impactante, visto que tem a ver com a prevalência do fantasma do fracasso que assola o cotidiano escolar e paralisa insistências criativas ao invés de produzi-las, o que faz com que, muitas vezes, os devires venham a ser dissipados a ponto de apagar os sujeitos (Carvalho, 2014).

1284 Educação \& Realidade, Porto Alegre, v. 41, n. 4, p. 1275-1287, out./dez. 2016. 
Para que se possa ir além de individualidades constituídas e firmadas nas disciplinarizações históricas das esferas de poderes que generalizam - mesmo que Foucault tenha afirmado a existência demasiada nas técnicas de dominação em seus estudos - trata-se, para Carvalho (2014, p. 112) de “[...] interrogar a história e qualquer de seus objetos no lugar de se deixar conduzir por eles”.

\section{Considerações Finais}

Ao fazer todo esse retorno à moral greco-romana e então resgatar a noção de cuidado de si Foucault buscou mostrar outro tipo de relação do homem consigo próprio (e com os outros). Tal relação não mais se baseia na universalidade de um fundamento nem em uma moralidade imposta tampouco em uma reflexão sistemática sobre um sujeito preexistente à cultura, ou seja, como algo já dado de antemão à experiência e à ação (sujeito-sempre-aí, segundo o preceito iluminista). Pelo contrário, Foucault acentua que na moral greco-romana o que havia era o respeito ao caráter individual da conduta humana, pois a escolha do modo de vida é uma questão pessoal e a elaboração - o trabalho projectual sobre a própria vida - se apoiava em uma série de técnicas que nada têm em comum com um caráter normativo nem pretendem se organizar em forma de código.

Nesse sentido, essa releitura da moral greco-romana torna-se para nós hoje uma tentativa de repensarmos criticamente os rumos metodológicos adotados nas mais diversas práticas educacionais e curriculares no esforço de recuperar a liberdade e a autonomia do educando que foram sendo massacradas com o avanço do capitalismo, com o desenvolvimento das novas relações de produção e também com os paradigmas da moralidade ocidental, baseados na normatividade, na universalização e na homogeneização.

É ainda nessa perspectiva que, segundo Dayrell (2007) que a pedagogia passa a ser interrogada na medida em que o ser humano passa a interrogar a si mesmo. Destarte, o cuidado de si retomado e reinterpretado por Foucault possibilita uma tomada de consciência crítica dos sujeitos em relação a si próprios, aos outros e ao mundo em que vivem, incitando a uma prática refletida da liberdade que extrapola os limites de sujeitamento historicamente produzidos através das individuações dos sujeitos. Sendo assim, o trabalho sobre nossos limites coincide com uma prática de liberação, de libertação de sujeitos, que parte de indagações que podem ser pontos de apoio das reflexões dos educadores na atualidade: “[...] o que é preciso aceitar ou não aceitar?" “[...] se não se aceita, o que se pode fazer?” (Foucault, 1994, p. 733). Para (não) finalizar, ficam aqui grafadas as palavras de Carvalho (2014, p. 114), como provocação, acerca da posição do sujeito na função-educador:

Educação \& Realidade, Porto Alegre, v. 41, n. 4, p. 1275-1287, out./dez. 2016. 
(Des)naturalizando Sujeitos e Práticas na Escola

Entramando como possibilidade de ação, o seu envolvimento com as experiências com as quais está suscetível de se defrontar sofre um golpe decisivo que se dá no âmbito da instalação inicial de um ponto de obstáculo haurido da própria condição de poder, de seus espaços, intervalos, desconexões, fissuras e limites. É quando o educador se abre ao inesperado, ao inclassificável, ao irredutível, ao divergente, ao imponderável, ao desvio da linha-limite.

Recebido em 05 de fevereiro de 2015 Aprovado em 26 de abril de 2016

\section{Referências}

CARVALHO, Alexandre Filordi de. Foucault e a Função-Educador. Ijuí: Unijuí, 2014. CARVALHO, Alexandre Filordi de. Foucault e a Função-Educador: sujeição e experiências de subjetividades ativas na formação do educador. Ijuí: Unijuí, 2010. CASTRILLÓN, Humberto. Foucault, Pedagogo? Revista Educación y Pedagogía, Medellín, Universidad de Antioquia, Facultad de Educación, v. 15, n. 37, p. 201216, 2003.

DALBOSCO, Cláudio. Pragmatismo, Teoria Crítica e Educação: ação pedagógica como mediação de significados. Campinas: Autores Associados, 2010.

DAYRELL, Juarez. A Escola 'faz' as Juventudes? Reflexões em torno da socialização juvenil. Educação \& Sociedade, Campinas, v. 28, n. 100, p. 1105-1128, 2007.

EIZIRIK, Marisa Faermann. Michel Foucault: um pensador do presente. 2. ed. revisada e ampliada. Ijuí: Unijuí, 2005.

FISCHER, Rosa Maria Bueno. Trabalhar com Foucault: arqueologia de uma paixão. Belo Horizonte: Autêntica, 2012.

FOUCAULT, Michel. Foucault étudie la raison d'Etat. In: FOUCAULT, Michel. Dits et Écrits IV - 1980-1988. Paris: Gallimard, 1994a. P. 37-40.

FOUCAULT, Michel. Le sujet et le pouvoir. In: FOUCAULT, Michel. Dits et Écrits IV- 1980-1988. Paris: Gallimard, 1994b. P. 222-242.

FOUCAULT, Michel. La Verdad y las Formas Jurídicas. Barcelona: Gedisa, 1995. FOUCAULT, Michel. A Ordem do Discurso: aula inaugural no Collége de France. 3. ed. São Paulo: Loyola, 1996.

FOUCAULT, Michel. A Hermenêutica do Sujeito. 2. ed. São Paulo: Martins Fontes, 2004

FOUCAULT, Michel. Microfísica do Poder. 26. ed. Organização: Roberto Machado. Rio de Janeiro: Graal, 2008.

FOUCAULT, Michel. Vigiar e Punir: o nascimento da prisão. 36. ed. Petrópolis: Vozes, 2009a.

FOUCAULT, Michel. Historia da Sexualidade I: a vontade de saber. 19. ed. Rio de Janeiro Graal 2009b.

FOUCAULT, Michel. O Governo de Si e dos Outros. São Paulo: Martins Fontes, 2011. FOUCAULT, Michel. As Técnicas de Si. In: FOUCAULT, Michel. Ditos \& Escritos IX: Genealogia da ética, subjetividade e Sexualidade. Rio de Janeiro: Forense Universitária, 2014. P. 264-298.

1286 Educação \& Realidade, Porto Alegre, v. 41, n. 4, p. 1275-1287, out./dez. 2016. 
LARROSA, Jorge; KOHAN, Walter. Apresentação da coleção. In: RANCIÈRE, Jaques. O Mestre Ignorante: cinco lições sobre a Emancipação Intelectual. Belo Horizonte: Autêntica, 2002. P. 1-38.

NIETZSCHE, Friedrich. Crepúsculo dos Ídolos. São Paulo: Col. L\&PM Pocket, 2009. PEÑA, Antonio. Foucault o de la Revaloración del Maestro como Condición de la Relación Pedagógica y como Modelo de Formación: una mirada pedagógica a la Hermenéutica del sujeto. Revista Educación y Pedagogía, Medellín, Universidad de Antioquia, Facultad de Educación, v. 15, n. 37, p. 219-232, 2003.

PLATÃO. Fedro/Cartas/Primeiro Alcibíades. Tradução: Benedito Nunes. 2. ed. Belém: EdUFPA, 2007.

SILVEIRA, Ederson Luís. Entre selfies, curtidas e subjetividades: sobre os sujeitos contemporâneos e o cuidado de si. O Corpo é Discurso, Vitória da Conquista, v. 1, n. 32, p. 04-10, 2014a.

SILVEIRA, Ederson Luís. Pensar com Foucault: história, sujeito e discurso. Cadernos Discursivos, Catalão/GO, v. 1 n. 1, p. 38 - 50, 2014b.

TIBURI, Marcia. Filosofia em Comum: para ler-junto. Rio de Janeiro: Record, 2008.

VEIGA-NETO, Alfredo. Foucault e a Educação. Belo Horizonte: Autêntica. 2005.

VEIGA-NETO, Alfredo. Editorial. Educação \& Realidade, Porto Alegre, v. 34, n. 2, p. 5-9, maio/ago. 2009.

VEYNE, Paul. Como se Escreve a História: Foucault revoluciona a história. Brasília: EdUnb, 1982.

Gabriel Nascimento da Silva Santos é graduado em Filosofia pelo Instituto Santo Tomás de Aquino - ISTA. É membro do grupo de pesquisas do Observatório da Juventude $(\mathrm{OJ} / \mathrm{CNPq})$, da Faculdade de Educação da UFMG, coordenado pelo Professor Juarez Dayrell. Trabalha na articulação de movimentos sociais pelos direitos juvenis junto ao Fórum das Juventudes. É membro e cofundador da Associação Brasileira de Incentivo à Ciência (ABRIC). Atualmente é docente no Colégio São Paulo da Cruz.

E-mail: gabriel.educ@gmail.com

Ederson Luis Silveira é mestre e doutorando em Linguística pela Universidade Federal de Santa Catarina-UFSC; pós-graduando em Ontologia e Epistemologia, graduado em letras Vernáculas pela Universidade Federal do Rio Grande-FURG (RS), membro do Grupo de Estudos em Territorialidades da Infância e Formação Docente (GESTAR/CNPq).

E-mail: ediliteratus@gmail.com

João Paulo de Lorena Silva é mestrando em Educação pela UFMG; Graduado em Filosofia pelo Instituto Santo Tomás de Aquino - ISTA. É membro do Grupo de Estudos e Pesquisas em Currículo e Culturas (GECC /CNPq), da Faculdade de Educação da UFMG, coordenado pela Professora Marlucy Alves Paraíso (FaE-UFMG). Atualmente é docente no Colégio Padre Eustáquio. E-mail: joaopaulopalmas@gmail.com 